\title{
EDUCAÇÃO AMBIENTAL COMO FERRAMENTA DE INFORMAÇÃO E PREPARO DAS LOCALIDADES RIBEIRINHAS PARA AS AUDIÊNCIAS PÚBLICAS NO ESTADO DO AMAZONAS
}

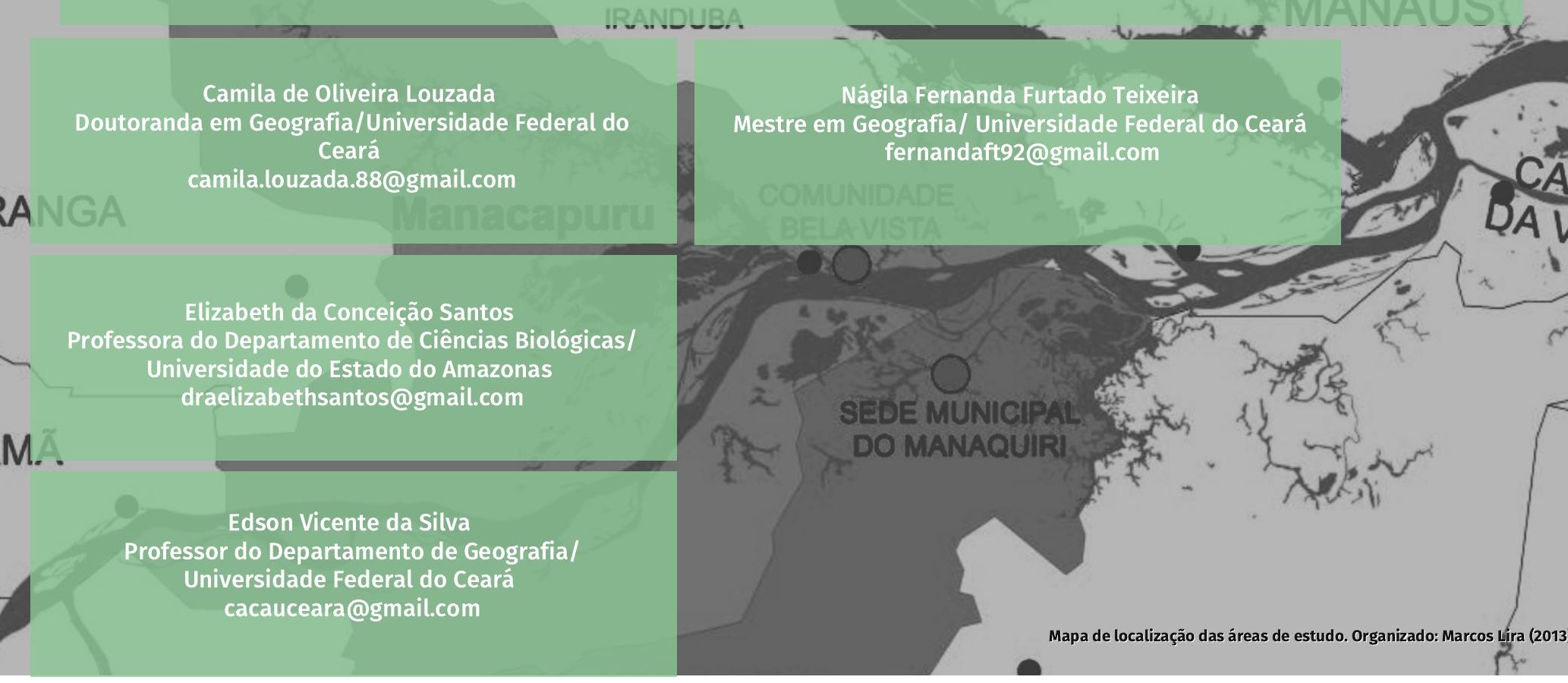

\section{RESUMO}

Historicamente a Amazônia sempre foi alvo de projetos de desenvolvimento audaciosos ao longo dos séculos, planejados de longa distância, sem qualquer preocupação com os danos ambientais sobre a região, muito menos com as populações tradicionais residentes ali. Diante disso, a presente pesquisa teve como objetivo, apresentar a educação ambiental como ferramenta de informação e preparo das localidades ribeirinhas do estado do Amazonas, previamente para as audiências públicas realizadas antes de grandes empreendimentos. Teve como metodologia a revisão bibliográfica e entrevistas semiestruturadas com moradores das localidades de Bela Vista e Manaquiri no Amazonas. Os resultados encontrados foram: que de fato, pouco ou quase nada, foi efetivado das políticas públicas para Educação Ambiental, em nenhuma esfera; os moradores da Bela Vista e Manaquiri se mostraram favoráveis em sua maioria, e temerosos com a perspectiva de reabertura da BR-319; quando indagados sobre a importância da Educação Ambiental para ajuda-los no preparo para as audiências públicas, tanto os moradores da Bela Vista como os moradores do Manaquiri, não souberam responder, com exceção de um entrevistado. Devido a isso, a maioria dos entrevistados se mostrou favorável a construção de grandes empreendimentos, como a nova ponte sobre o rio Solimões e a reabertura da BR-319.

Palavras-chave: Educação Ambiental; Ribeirinhos; Bela Vista; Manaquiri; Audiências Públicas.

\section{RESUMEN}

Historicamente la Amazónia siempre fué alvo de proyectos de desarrollo audaciosos al largo de los siglos, planificados a partir de largas distancias, sin cualquiera procupacipón sobre los daños ambientales en la región, mucho menos com las populaciones tradicionales locales. Delante del hecho, la presente investigación tuvo como objectivo presentar la educación ambiental como herramienta de información y preparo de las localidad ribeiriñas de la província del Amazonas, para la logrando audiéncias públicas antes que se consoliden los grandes proyectos. Como metodologia se desarrollaran revisiónes bibliográficas y encuestas semiestruturadas con los habitantes de las comunidades de Bela Vista e Manaquiri en el Amazonas. Los resultados obtenidos encontrados fuerón: i) que de hecho poco o casi nada fué efectivado de las políticas públicas para la Educação Ambiental, en ninguna esfera; ii) la mayoria de los moradores da Bela Vista y Manaquiri se muestraran favorábles, pero también temerosos com la perspectiva de reabertura de la BR319; iii) cuando indagados sobre la importáncia de la Educación Ambiental para ayudarlos en el preparo para las audiências públicas, tanto los moradores da Bela Vista como los moradores de Manaquiri, no souberan responder, con excepción de un encuestado. Por eso la mayoria de los encuestados se mostró favorable a la construcción de grandes empreendimentos, como la nueva puente sobre el rio Solimones y la reabertura de la BR-319.

Palabras clave: Educación Ambiental; Ribeiriños; Bela Vista; Manaquiri; Audiéncias Públicas. 


\section{INTRODUÇÃO}

A Educação Ambiental foi primeiramente concebida por movimentos ecológicos após 1950, com o objetivo de chamar a atenção para a finitude dos elementos da natureza, e sua exploração descontrolada. Diante disso Carvalho (2006) propõe sensibilizar os cidadãos do mundo para que eles possam desenvolver ações socioambientais, pensando no bem coletivo, e não individual, ou de pequenos grupos.

o marco principal desse período de incertezas culminou na publicação do livro Primavera Silenciosa; nele a autora chama a atenção para o uso irracional de pesticidas químicos principalmente o DDT (dicloro-difeniltricloroetano) e responsabilidade da ciência e os limites tecnológicos, questionava o direito moral do governo de deixar seus cidadãos desprotegidos diante de tais substâncias que eles não poderiam evitar fisicamente, nem questionar publicamente. Essa arrogância insensível só poderia levar a destruição do mundo vivo. "Será que alguém acredita que é possivel lançar tal bombardeio de venenos na superficie da Terra sem torná-la imprópria para toda a vida? perguntava ela. Eles não deviam ser chamados de 'inseticidas', e sim "biocidas'" (CARSON, 2013, p. 15).

Carson (2013) vai além, ao afirmar que um dos direitos dos cidadãos mais básicos, é proteger seu lar contra a invasão de venenos aplicados por outras pessoas, chamando a atenção da sociedade estadunidense para 0 uso descontrolado de pesticidas nas lavouras americanas, que prejudicavam além do meio ambiente físico em larga escala, como também a saúde da população. Após a publicação dessa obra, foram iniciadas investigações estaduais e federais nos EUA, para refutar os argumentos da autora que terminaram por serem comprovados, e após inúmeras pressões de ambientalistas, o governo americano foi obrigado a criar um pacote de leis contra a contaminação invisivel, muito posteriormente proibindo o uso DDT nos EUA, mas exportando para todo o mundo (CARSON, 2013).

Como os movimentos ecológicos ultrapassaram as preocupações locais, e se transformaram em globais, gerou grande desconforto na sociedade mundial, tanto científica quanto civil, o que resultou em importantes encontros mundiais, a começar pela primeira Conferência Mundial das Nações Unidas sobre Meio Ambiente Humano, que aconteceu em 1972 em Estocolmo, na Suécia, e contou com a participação de representantes de 113 países, onde foram divulgados aos participantes "a devastação que ocorria na natureza, delirou - se que o crescimento humano precisaria ser repensado imediatamente" (PEDRINI, 1997, p.26). Dessa conferência resultaram dois importantes documentos: "A Declaração sobre Meio Ambiente Humano", que descrevia vinte e sete princípios comuns à sociedade mundial para preservar e melhorar a relação do homem com o meio ambiente e o "Plano de Ação 1994 Mundial", que recomendava a capacitação de professores e o desenvolvimento de novos métodos e recursos institucionais para a Educação Ambiental (PEDRINI, 1997).

Três anos depois de Estocolmo acontece, a Conferência de Belgrado na Yugoslávia, antiga União Soviética. Nessa conferência os ânimos se exaltaram pois os países considerados subdesenvolvidos acusaram os países desenvolvidos de quererem limitar o desenvolvimento econômico dos países pobres, "usando políticas ambientais de controle da poluição como meio de inibir a competição no mercado internacional" (DIAS, 2000, p.79). Apesar dos ânimos acalorados, essa conferência resultou em um importante documento em nivel mundial: a "A Carta de Belgrado" que priorizava a erradicação da pobreza, do analfabetismo, da fome, da exploração e dominação humana, e 
sugeria também a criação de um Programa de Educação Ambiental (PEDRINI, 1997).

Outra Conferência marcante na história da Educação Ambiental foi a Conferência de Tbilisi realizada em 1977, que determinava os objetivos, estratégias, características e recomendações para se alcançar uma Educação verdadeiramente Ambiental. Sobre isso Junior (2005) destaca que para se ter, uma Educação Ambiental, deve-se "promover a cooperação e o diálogo entre indivíduos e instituições, com a finalidade de criar novos modos de vida e atender as necessidades básicas de todos, sem distinções étnicas, físicas, de gênero, idade, religião ou classe social" (JUNIOR, 2005, p. 15 ).

Talvez não seja necessário criar novos modos de vida, em todos os lugares, basta conhecer e difundir os modos de vida tradicionais de cada lugar, a exemplo do modo de vida ribeirinho presente na Ilha do Januário no rio Amazonas (LOUZADA, 2018), onde sua população produz seu próprio desenvolvimento procurando alcançar uma harmonia/adaptação com a natureza à sua volta.

\section{METODOLOGIA}

A presente pesquisa foi realizada em duas etapas: revisão bibliográfica e entrevistas semiestruturadas com os moradores das localidades de Bela Vista e Manaquiri no Amazonas.

$\mathrm{Na}$ revisão bibliográfica, primeiramente procurou-se estabelecer uma sequência histórico da Educação Ambiental em escala mundial, nacional, estadual, com destaque para a Política Nacional de Educação Ambiental, e posteriormente a Política Estadual de Educação Ambiental no estado do Amazonas, e, o que, de fato foi executado dessa política, desde sua homologação em 2012.

$\mathrm{Na}$ segunda etapa da pesquisa, foram entrevistados 40 moradores nas localidades de
Bela Vista município de Manacapuru, e 40 pessoas na sede do município de Manaquiri, de mesmo nome.

Nas entrevistas semiestruturas buscou-se saber qual o posicionamento dos entrevistados, sobre: a construção de uma nova ponte sobre o rio Solimões; a perspectiva de reabertura da BR319; e como Educação Ambiental poderia ajudalos no preparo para as Audiências Públicas.

\section{RESULTADOS E DISCUSSÕES}

\section{O Brasil e a Política Nacional de Meio Ambiente}

Atendendo aos acordos firmados internacionalmente o Brasil, foi criada a lei sobre a Política Nacional do Meio Ambiente - Lei no 6.938 , de 31 de agosto de 1981, que dispunha no art. 2, por objetivos;

[...] a preservação, melhoria e recuperação da qualidade ambiental propícia à vida, visando assegurar, no País, condições ao desenvolvimento sócio econômico, aos interesses $\mathrm{da}$ segurança nacional e à proteção da dignidade da vida humana, atendidos os seguintes princípios: I - ação governamental na manutenção do equilíbrio ecológico, considerando o meio ambiente como um patrimônio público a ser necessariamente assegurado e protegido, tendo em vista o uso coletivo; II - racionalização do uso do solo, do subsolo, da água e do ar; Ill planejamento e fiscalização do uso dos recursos ambientais; IV - proteção dos ecossistemas, com a preservação de áreas representativas; $\mathrm{V}$ - controle e zoneamento das atividades potencial ou efetivamente poluidoras; $\mathrm{VI}$ - incentivos ao estudo e à pesquisa de tecnologias orientadas para o uso racional e a proteção dos recursos ambientais; VII acompanhamento do estado da qualidade ambiental; VIII - recuperação de áreas degradadas; IX - proteção de áreas ameaçadas de degradação; $X$ educação ambiental a todos os níveis de 
ensino, inclusive a educação da comunidade, objetivando capacitá-la para a participação ativa na defesa do meio ambiente (BRASIL apud LOUZADA, 2014, p. 195)

A Política Nacional de Meio Ambiente foi absolvida pela Constituição Brasileira de 1988, mais especificamente no artigo 225 , onde também concebe o conceito de desenvolvimento sustentável, como um direito de todos os cidadãos brasileiros viverem no meio ambiente ecologicamente equilibrado, bem de uso comum do povo e essencial á sadia qualidade de vida, "impondo se ao Poder Público e á coletividade o dever de defendê-lo e preservá-lo para as presentes e futuras gerações" (BRASIL, 1988, p.7).

No processo de formação de profissionais defensores da Educação Ambiental, o Brasil saiu na frente, criando leis que tornaram obrigatória a "Educação Ambiental em todos os níveis de ensino e a conscientização pública da população para preservação do meio ambiente" (BRASIL, 1988, p.103).

Para consolidar a lei, foi criado em 1989 o Instituto Brasileiro do Meio Ambiente - IBAMA autarquia federal que teve como função coordenar e executar a Política Nacional do Meio Ambiente e a preservação e conservação de uso racional dos recursos naturais, Brasil (1989). No entanto, em sua estrutura administrativa, apresentada, segundo Brasil (1989a), não há cargos ou seções específicas para trabalhar a Educação Ambiental, embora muitos autores relatem existir uma Divisão de Educação Ambiental no órgão supracitado.

Em 27 de Abril de 1999, foi criada, pelo Decreto Lei no 9.795, a Política Nacional de Educação Ambiental- ProNEA;

Art. 1o Entendem- se por educação ambiental os processos por meio dos quais o indivíduo e a coletividade constroem valores sociais, conhecimentos, habilidades, atitudes e competências voltadas para promover a conservação do meio ambiente, bem de uso comum do povo, essencial à sadia qualidade de vida e sua sustentabilidade. (BRASIL, 1999, p.1)

Segundo Brasil (1999), o ProNea tem como ações assegurar;

[...] no âmbito educativo, a integração equilibrada das múltiplas dimensões da sustentabilidade - ambiental, social, ética, cultural, econômica, espacial e política - ao desenvolvimento do País, resultando em melhor qualidade de vida para toda a população brasileira, por intermédio do envolvimento e participação social na proteção e conservação ambiental e da manutenção dessas condições ao longo prazo. Nesse sentido, assume também as quatro diretrizes do Ministério do Meio Ambiente: Transversalidade, Fortalecimento do Sistema, Sustentabilidade, Participação e controle social (BRASIL, 1999, p.1).

A legislação parte do princípio de que a Educação Ambiental deve estar permanente na educação nacional, em todos os níveis do processo educativo, de caráter formal e não formal (BRASIL, 1999, p.1).

Esse arcabouço legal permitiria que a Educação Ambiental, efetivamente, no âmbito nacional, fosse implementada no ensino formal, em todos os níveis, porém a rejeição da "obrigatoriedade", considerada nociva no momento democrático que se vive, permite que a legislação não seja cumprida, de acordo com os marcos nacionais e internacionais firmados nos eventos que constituem o seu processo histórico (SANTOS, 2013, p.844). Essa situação conduz a reflexão de que existem interesses em que não se efetive a Educação Ambiental no ensino formal e não formal, para que os governantes e grandes empresas continuem a impactar cada vez mais a natureza, sem a preocupação do cumprimento das legislações vigentes. Nesse sentido; 
[...] poderiam ser formadas novas gerações de professores, que encontrariam em sua profissão o sentido de uma missão cívica e ética para que cada aluno ou estudante possa enfrentar os problemas de sua vida profissional, e de sua vida de cidadão, do dever de sua sociedade, de sua civilização na humanidade (MORIN apud SANTOS, 2013, p.844).

\section{Política de Educação Ambiental no Estado do Amazonas}

Acompanhando as leis federais, os estados brasileiros passaram a criar leis quase sempre dispondo sobre a proteção do meio ambiente. No estado do Amazonas a Lei no 1.532 de 06 de julho de 1982, tornou-se a primeira lei no estado a discorrer sobre a Política Nacional de Meio Ambiente, criando a Política Estadual da Prevenção e Controle da Poluição, Melhoria e Recuperação do Meio Ambiente, e de Proteção aos Recursos Naturais (AMAZONAS apud LOUZADA 2014 p.197)

A lei tem como objetivos;
[...] fixar diretrizes da ação governamental com vistas à proteção de Meio Ambiente, à conservação e proteção da flora, da fauna e das belezas cênicas e ao uso racional do solo , da água e ar ; Contribuir para a racionalização do processo do desenvolvimento econômico e social , procurando atingir a melhoria dos níveis da qualidade ambiental, tendo em vista - bem estar da população; Propor critérios de exploração e uso racional dos recursos naturais, objetivando o aumento de produtividade, sem prejuízo à saúde; Incentivar programas e campanhas de esclarecimentos com vistas à estimulação de uma consciência publica voltada para o uso adequado dos recursos naturais, e para a defesa e a melhoria da qualidade ambiental; Estabelecer critérios para reparação dos danos causados pelo agente poluidor $\mathrm{e}$ predador (AMAZONAS, 1982, p.2).

E em 14 de junho de 1989, através da Lei no 1.905 foi criado o Instituto de Desenvolvimento dos Recursos Naturais e Proteção Ambiental do Estado do Amazonas - IMA/AM. Segundo o IPAAM (2014), o órgão tinha como função executar a Política Ambiental no estado dando início, ao processo de controle ambiental sistemático.

Cinco anos depois, o governo federal através da Lei no 1.282 de 1994, estabelece que a Floresta Amazônica deva ser protegida da exploração madeireira, que somente poderá ser feita de forma sustentável, salvo quando for autorizado pelo Zoneamento Ecológico Econômico, e sobre o uso do solo de forma alternativa (BRASIL, 1994). Dois anos depois, em 1996, o governo do estado do Amazonas fundou o Instituto de Proteção Ambiental do Amazonas - IPAAM através da Lei no 17.033 de 11, de março de 1996, resultado da fusão da SEMACT (Secretaria do Meio Ambiente, Ciência e Tecnologia) e do IMA/AM (Instituto de Desenvolvimento dos Recursos Naturais e Proteção Ambiental do Estado do Amazonas), absorvendo cargos dos dois órgãos e suas "obrigações" legais.

O Instituto de Desenvolvimento dos Recursos Naturais e Proteção Ambiental do Estado do Amazonas - IPAAM, passou a ser vinculado, em fevereiro de 2003, á Secretaria de Estado Meio Ambiente e Desenvolvimento Sustentável SDS, como órgão executor da Política de Controle Ambiental do Estado do Amazonas (IPAAM 2014).

Por meio do Decreto Estadual no 25.043 de 1응 de Junho de 2005, foi instituída a Comissão Interinstitucional de Educação Ambiental do Estado do Amazonas - CIEA-AM, que tem como função, "planejar, executar, acompanhar e avaliar a execução dos trabalhos de Educação Ambiental no Estado além de articular-se com outras instituições federais e municipais" (AMAZONAS, 2014, p.1). 198 
A CIEA-AM tem mandato bianual alternado entre a SDS (Secretaria de Estado Meio Ambiente e Desenvolvimento Sustentável) e a SEDUC (Secretária de Estado da Educação e Qualidade do Ensino) (AMAZONAS, 2014).

Em 2008, foi instituída a Política de Educação Ambiental do Estado do Amazonas, através da Lei no 3.222 de 02 de fevereiro, entretanto, apesar de a lei ter noventa dias para a sua regulamentação, ouvidos o Conselho Estadual de Meio Ambiente, somente em 29 de junho de 2012 é que o Decreto no 555 foi assinado pelo governado Omar Aziz e publicado no Diário Oficial do Estado do Amazonas (SANTOS, 2012, p.844)

A Política de Educação Ambiental do Estado do Amazonas tem como metas; a Criação do Comitê Assessor Multidisciplinar como órgão de assessoramento da CIEA para apoiar a Política Estadual de Educação Ambiental, formado por 16 Instituições parceiras; estabelece prazo de um ano para a elaboração do Programa Estadual de Educação Ambiental; estabelece a obrigatoriedade para os poderes executivos do Estado e dos Municípios de criarem coordenações multidisciplinares de Educação Ambiental nas secretarias de educação e de meio ambiente para fortalecimento na implantação de políticas e programas nacional, estadual e municipal neste segmento; garantia de recursos orçamentários e financeiros para a realização de atividades e para o cumprimento dos objetivos da Política de Educação Ambiental (AMAZONAS, 2014, p.2).

Faz-se necessário salientar que muito pouco, do que foi proposto para o estado, de fato foi executado, inclusive a não inserção da Educação Ambiental em todos os cursos de formação de professores, na própria Universidade do Estado do Amazonas a UEA.

Sobre isso, Santos apud Rodriguez e Silva (2013, p.197)

\section{[...] reconhecem que a Educação}

Ambiental deverá ter um papel fundamental na mudança das mentalidades e na incorporação dos fundamentos do pensamento ambientalista, como também do pensamento sustentabilista, justificando a sustentabilidade como uma propriedade integradora e uma emergência dos sistemas ambientais e socioeconômico-culturais (SANTOS apud RODRIGUEZ e SILVA, 2013, p.197)

Santos (2013) vai além, infelizmente torna-se necessário reconhecer que muitas vezes as políticas públicas, definidas na esfera federal, estadual ou municipal, refletem uma contradição entre o discurso e a prática, uma vez que os próprios órgãos públicos, a luz da interpretação das brechas da legislação ambiental, licenciam obras sob o argumento de melhoria da qualidade de vida da população, mas com impactos ambientais irreversiveis, que são justificados com "medidas compensatórias" irrelevantes (SANTOS, 2013, p.840).

\section{Educação Ambiental como ferramenta de informação para as localidades ribeirinhas antes das Audiências Públicas.}

Passando-se trinta e seis anos da criação da Política Estadual da Prevenção e Controle da Poluição, Melhoria e Recuperação do Meio Ambiente, e de Proteção aos Recursos Naturais do estado do Amazonas, pouco ou quase nada de fato foi efetivado no sentido de proteger o meio ambiente, e formar profissionais capacitados em Educação Ambiental nem no nível formal, muito menos no nível não formal.

Diante desses fatos, tornou-se necessário projetar a efetiva Educação Ambiental para as localidades ribeirinhas do Amazonas, a começar pelas localidades de Bela Vista e Manaquiri, previstas para serem as cabeceiras da nova ponte, que será construída sobre o rio Solimões, afim de concluir a efetiva reabertura da BR-319 (LOUZADA, 2014). 
Educação Ambiental viria no sentido de fornecer informações para as populações ribeirinhas, direta ou indiretamente sobre empreendimentos similares, já construídos em ambientes semelhantes, de forma a propiciar embasamento teórico e, se possivel, prático, na formação de uma opinião fundamentada, seja individual ou coletiva. Isso porque, muitas pessoas não informadas tendem a considerar as Audiências Públicas, realizadas antes dos empreendimentos, como espaços onde não são permitidos questionamentos, quando na verdade, é o que se deve fazer, pois as Audiências Públicas têm como principal função consultar a opinião pública, sobre o empreendimento a ser construído. Contudo, se o público consultado não tiver informações sobre o empreendimento, ou qualquer outro semelhante como poderá opinar, em algo que lhes é completamente desconhecimento?

Buscando responder tal pergunta, foram aplicados questionários semiestruturados, para moradores das localidades da Bela Vista município de Manacapuru, localizado na margem esquerda do rio Solimões, e Manaquiri, município de mesmo nome, localizado na margem direita do mesmo rio (Figura 1).

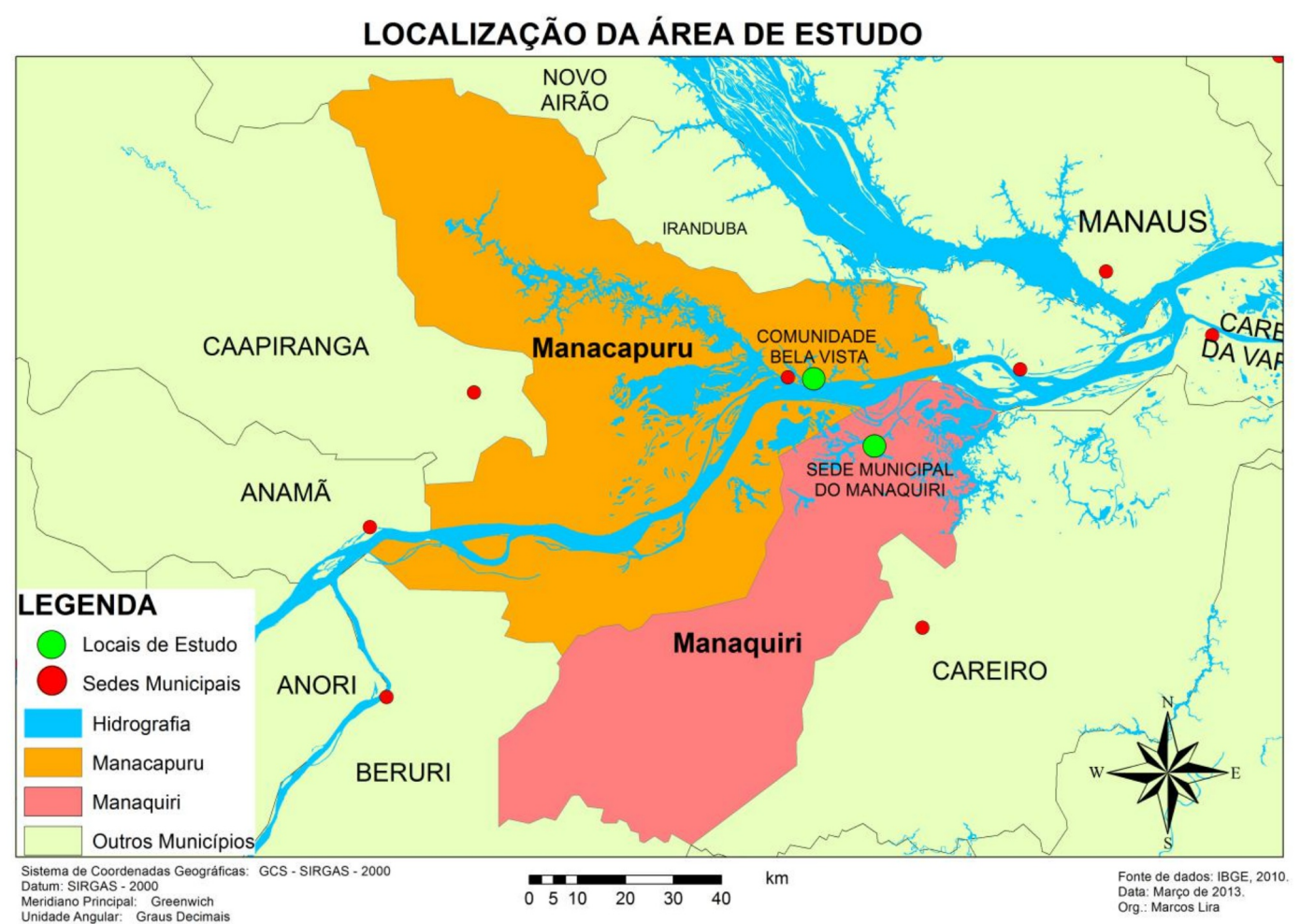

LOCALIZAÇÃO DA ÁREA DE ESTUDO

Figura 1: Mapa de localização das áreas de estudo.

Organizador: Marcos Lira (2013).
Na localidade de Bela Vista foram aplicados 40 questionários de maneira aleatória, sendo $57 \%$ homens entrevistados e $43 \%$ mulheres; com idades variando entre 14 e 77 anos; de naturalidades diversas: Rondônia, Roraima, Amazonas (Bela Vista, Itacoatiara, Coari, Manaquiri, Lábrea, Cruzeiro do Sul, Alto Juruá).

Perguntados sobre o seu posicionamento em relação à construção de uma ponte sobre o rio Solimões, que teria a localidade da Bela Vista como uma de suas cabeceiras, cerca de $92 \%$ dos entrevistados se mostraram favoráveis ao empreendimento contra $8 \%$ que se mostraram contrários à obra.

$\mathrm{Na}$ localidade de Manaquiri também foram entrevistadas 40 pessoas de maneira aleatória sendo, $55 \%$ mulheres e $45 \%$ homens, com idades variando entre 22 e 83 anos, e com naturalidades mais diversas: Colômbia, Venezuela, Brasil (Ceará, Parnaíba, Piauí, Pará, Amazonas (Manaus, Iranduba, Eirunepé, Coari, Anamã, Careiro da Várzea).

Dos moradores do Manaquiri, somente $60 \%$ dos entrevistados se mostrou favorável a construção de uma ponte sobre o rio Solimões, sendo que, $27 \%$ se mostrou extremamente receosa com a perspectiva de um possível aumento da violência, citando exemplos do que aconteceu, com a cidade de Iranduba após a inauguração da Ponte Rio Negro, em 2011 (LOUZADA e SANTOS, 2016); e somente $8 \%$ se mostraram totalmente contrários á construção da ponte, pois acreditam que os beneficios

do 
empreendimento, não superariam seus malefícios, destacando a preocupação com a destruição da floresta. Os entrevistados das duas localidades foram perguntados se participariam das Audiências Públicas sobre a reabertura da BR-319, responderam conforme o Gráfico 1:

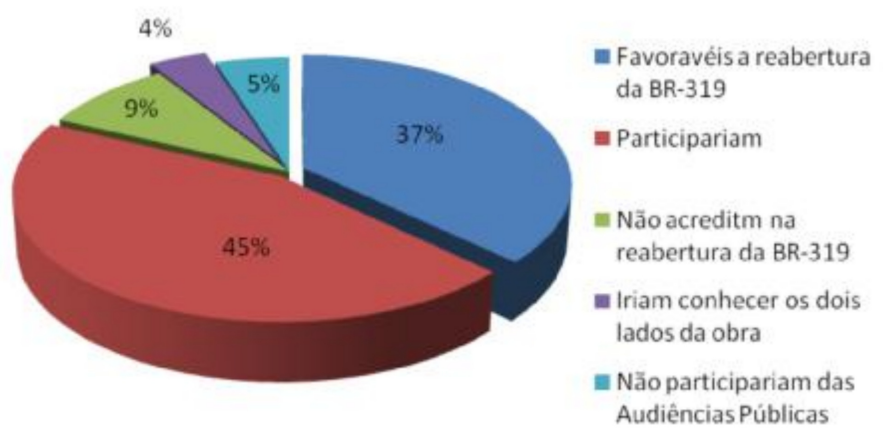

Gráfico 1: Respostas dos entrevistados da Bela Vista, sobre a participação nas Audiências Públicas.

Fonte: Camila Louzada (2013)

A maioria, 45\% da população, mostra-se disposta a participar de Audiências Públicas sobre a reabertura da BR-319, mas somente se chegassem a ser convocados; $37 \%$ se mostrou favorável à reabertura da rodovia, afirmando que a mesma já foi aberta um dia, sendo necessária ser novamente asfaltada, sinalizada e ter suas pontes refeitas, já que praticamente não existem mais. Ainda desse total $5 \%$ disseram que não desejariam participar, com destaque para uma colocação "Filha eu não iria, pois não se decide o que já foi decidido" (comunicação pessoal de um entrevistado).

Já na localidade do Manaquiri o percentual de pessoas favoráveis a participação em Audiências Públicas sobre a reabertura da BR319 chegou a 75\% (Gráfico 2).

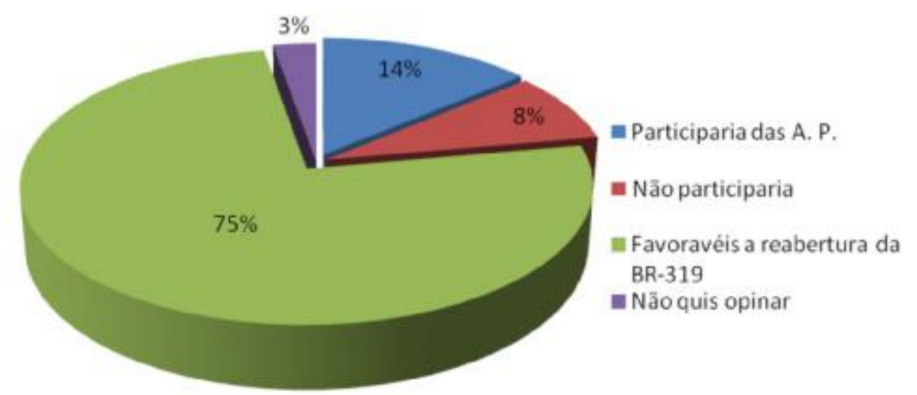

Gráfico 2: Respostas dos entrevistados do Manaquiri, sobre a participação nas Audiências Públicas.

Fonte: Camila Louzada (2013).
A maioria $75 \%$ dos entrevistados afirmaram ser a favor da reabertura da BR-319, por isso participariam das audiências públicas, $14 \%$ disseram que somente participariam e $8 \%$ que não participariam; e 3\% dos entrevistados optaram por não opinar.

O principal argumento utilizado para o posicionamento favorável à reabertura da BR319 foi de que seria possível conhecer outros municípios do estado pela estrada, e chegar a outros estados de carro, porque não os agradava a possibilidade de viajar de avião.

Perguntados sobre se a Educação Ambiental poderia ajuda-los no preparo para as Audiências Públicas, tanto os moradores da Bela Vista como os moradores do Manaquiri, não souberam responder, com exceção de um entrevistado do Manaquiri que afirmou "Que se, os moradores fossem informados dos beneficios e maleficios de qualquer obra, bem antes das audiências públicas, a gente não ficaria calado lá, acreditando nos sabichões, que são pagos pelos poderosos, para enfiar goela abaixo as obras, e a gente que se lasca depois" (comunicação pessoal de um entrevistado).

Como sabiamente o entrevistado descreveu, não existe qualquer preparo das localidades ribeirinhas para as Audiências Públicas, e durante as audiências somente são destacados os benefícios dos empreendimentos e nunca os seus impactos para as localidades diretamente ou indiretamente afetadas, de certa forma convencendo os presentes daquilo que já está planejado.

Diante dessa realidade se faz necessário: informar e capacitar a população através da Educação Ambiental de modo a contribuir para a tomada de decisão de forma consciente e bem informada; viabilizar o acesso dos moradores a diversas fontes de pesquisa sejam elas publicadas em artigos, livros, jornais, e informações veiculadas pela internet, que permitam obter pesquisas confiáveis sobre os 
aspectos positivos e negativos, relacionados aos impactos provocados por obra semelhantes; realizar palestras com as diversas categorias de profissionais sejam eles, favoráveis ou contrários à empreendimentos na Amazônia, de modo a discutir os avanços e retrocessos na qualidade de vida dos amazônidas; promover oficinas de Educação Ambiental que permitam a análise crítica dos problemas ambientais, e suas interrelações dinâmicas, relacionando as causas e consequências.

Diante da convicção de que essas intervenções com a Educação Ambiental significam, na maioria das vezes oposição, ao que pretende o poder público, há de se verificar como concretizar efetivamente essas propostas de Educação Ambiental, considerando ainda a importância do ambiente amazônico.

\section{CONSIDERAÇÕES FINAIS}

A Amazônia sempre foi palco de projetos audaciosos ao longo dos séculos, exemplo do I e II ciclo da borracha, a construção da BR-230 (Trasamazônica), BR-020 (Belém - Brasília), a BR319 (Manaus - Porto Velho), isso sem falar das hidrelétricas a começar pelo fracasso da hidrelétrica de Balbina e "terminar" em Santo Antônio, Belo Monte e Girau. Todos projetos gigantescos planejados de longa distância sobre a região, sem qualquer preocupação com os danos ambientais e com as populações tradicionais residentes ali.

Como sabiamente descreveu Santos (2012), o maior destruidor da natureza é o estado. Pensando nisso e em todas as grandes obras já implantadas no estado do Amazonas, e a perspectiva de reabertura da BR-319 e a construção de uma ponte sobre o rio Solimões, - presente trabalho ousou apresentar a Educação Ambiental como ferramenta de informação para as populações ribeirinhas das localidades de Bela Vista e Manaquiri, com o objetivos de fornecer informações sobre empreendimentos similares já construídos na Amazônia, apresentando seus benefícios e seus impactos nas localidades direta e indiretamente afetadas pelos empreendimentos já executados, para que os moradores tivessem maior embasamento possivel na tomada de decisão nas Audiências Públicas.

Quando os moradores da Bela Vista e do Manaquiri foram indagados sobre seus posicionamentos, com a perspectiva de construção de uma ponte sobre o rio Solimões, na Bela Vista $92 \%$ dos entrevistados se mostraram favoráveis ao empreendimento, e 8 \% se mostraram contrários à obra. No Manaquiri a porcentagem de favoráveis chegou a $60 \%$, e também $8 \%$ contrários, todavia surgiu um terceiro posicionamento que alcançou $27 \%$ que são os moradores que se mostraram extremamente receosos com a perspectiva de um possivel aumento da violência, citando exemplos do que aconteceu com a cidade de Iranduba após a inauguração da ponte Rio Negro em 2011.

E perceptivel a empolgação com a construção de uma ponte sobre o rio Solimões, entretanto, será que os moradores das duas localidades foram informados, dos possiveis impactos que isso trará, acredito que não.

Indagados sobre a perspectiva de reabertura da BR-319, os moradores da Bela Vista não se mostraram tão otimistas, pois somente $37 \%$ acreditam na reabertura da BR-319, contra $75 \%$ dos entrevistados do Manaquiri, que foram os mais otimistas com a reabertura da BR-319. Talvez, isso se dê, porque de fato pouco ou quase nada, da Política Pública da Educação Ambiental chegou a ser implementada no estado do Amazonas nos últimos seis anos, nem se quer no ensino formal, quanto mais no não formal.

Quando os entrevistados foram perguntados sobre a importância da Educação Ambiental para ajuda-los no preparo para as audiências públicas, de oitenta entrevistados somente um, 
conseguiu responder afirmando "Que se, os moradores fossem informados dos beneficios e maleficios de qualquer obra, bem antes das audiências públicas, a gente não ficaria calado lá, acreditando nos sabichões, que são pagos pelos poderosos, para enfiar goela abaixo as obras, e a gente que se lasca depois" (comunicação pessoal de um entrevistado).

Como sabiamente o entrevistado descreveu, não existe qualquer preparo das localidades ribeirinhas para as Audiências Públicas, quando essa deveria ser uma das funções da Política Estadual de Educação Ambiental do Estado do Amazonas, todavia isso não acontece, pois não é de interesse dos governantes que isso seja feito.

\section{REFERÊNCIAS}

AMAZONAS. Ministério Público do Amazonas:

\section{Consulta Pública sobre as Unidades de}

Conservação da BR-319. Manaus, 2014.

Disponivel em: http://www.sds.am.gov.br/201109-27-04-55-44/noticias/slide-show/consultaspublicas-das-unidades-de-conservacao-da-br319-sao-finalizadas. Acessado em Abril de 2014.

AMAZONAS. Lei estadual no 1.532 de 06 de Julho de 1982. Política Estadual de Meio Ambiente.

Manaus, Biblioteca Pública do Amazonas. Texto impresso, 1982.

BRASIL. Política Nacional do Meio Ambiente, Lei no 6.938 de 31 de Agosto de 1981, Brasília.

Disponivel em :

http://www.planalto.gov.br/ccivil_03/leis/16938. htm . Acessado em Janeiro de 2014.

BRASIL. Constituição da República Federativa do Brasil de 1988. Brasília. Disponivel em:

http://www.planalto.gov.br/ccivil_03/constituic ao/constituicao.htm . Acessado em Janeiro de 2014.

BRASIL. Lei no 7.735 de 22 de Fevereiro de 1989. Criação do IBAMA. Brasília. Disponível em: http://www.planalto.gov.br/ccivil_03/leis/l7735. htm . Acessado em Janeiro de 2014.
BRASIL. Lei no 1.282 de 1994, que estabelece o uso sustentável da floresta Amazônica, Brasília, 1994.

BRASIL. Decreto lei no 9.795 de 27 de Abril de 1999. Diário Oficial da União. Brasília, 1999.

CARVALHO, Isabel. Educação Ambiental:

Formação do Sujeito Ecológico. 2a Ed. São Paulo, Cortêz, 2006.

CARSON, Rachel. Primavera Silenciosa. São

Paulo. Editora Gaia, 2013.

DIAS, G. F. Educação Ambiental: princípios e práticas. 6a ed. São Paulo: Gaia, 2000. Disponivel em:

http://www.mma.gov.br/estruturas/educamb/_ arquivos/livro_ieab.pdf. Acessado em Junho de 2012.

IPAAM. Histórico da Política Ambiental do Estado do Amazonas, Manaus, 2010. Disponível em:

http://www.ipaam.am.gov.br/pagina_interna.ph p?cod=1. Acessado em Janeiro de 2014.

JUNIOR, A. P. E PELICIONI, M. Educação

Ambiental e Sustentabilidade. 1a ed. BarueriSP. Manolie, 2005.

LOUZADA, Camila. As grandes obras para reabertura da BR-319 e seus impactos nas localidades ribeirinhas do Rio Solimões: Bela Vista e Manaquiri, no Amazonas.

2014. Dissertação (Mestrado em Geografia) Programa de Pós-Graduação em Geografia, Universidade Federal do Amazonas, 2014. Disponível em:

<http://tede.ufam.edu.br/bitstream/tede/3983/

2/Disserta\%C3\%A7\%C3\%A30\%20-\%20

Camila\%20de\%200liveira\%20Louzada.pdf>. Acesso em: 12 jan. 2017.

LOUZADA, Camila; SANTOS, Elizabeth.

Reconfiguração espacial do município de Iranduba, com a inauguração da Ponte Rio Negro, Amazonas, Brasil. Revista Cesumar, v.21, N.1 - Maringá- Janeiro/Junho de 2016, ISSN: 1516- 
2664.

LOUZADA, Camila; BRANDÃO, Jesuéte; SANTOS,

Elizabeth. 0 modo de vida ribeirinho na Itha do Januário no rio Amazonas. Revista Boletim

Goiano de Geografia, v.38, n.1, p.178- 199, jan/abr. 2018, ISSN: 1984-8501.

PEDRINI, A. Educação Ambiental: reflexões e práticas contemporâneas. 50ed.

Petrópolis, Vozes, 1997.

SANTOS, E; RODRIGUEZ, M. EDUCAÇÃO AMBIENTAL E TRANSDISCIPLINARIDADE: PARA REPENSAR 0 DESENVOLVIMENTO NO COMBATE À CRISE PLANETÁRIA. VI Simpósio Brasileiro sobre Meio Ambiente e Desenvolvimento Sustentável do Semiárido, Mossoró - RN, 2013.

SANTOS, Elizabeth. 0 maior destruidor da Natureza é o estado. Manaus, 2012. III Congresso Brasileiro de Educação Ambiental Aplicada e Gestão Territorial. Manaus, 27 a 29 de Novembro de 2012. ISBN 978-85-7883-273-5. 